\title{
Low Background Glass Substrates for Microanalysis
}

\author{
E.S. Windsor, C.J. Zeissler, S.A. Wight, E.B. Steel and D.H. Blackburn \\ National Institute of Standards and Technology, Gaithersburg, MD 20899
}

The light microscope and the environmental scanning electron microscope (ESEM) are complementary techniques for microanalysis of particulate samples. Often, they are the first techniques employed because they are non-destructive and do not require that the sample be given a conductive coating prior to analysis.

Particles are supported on substrates for analysis with both the light microscope and the ESEM [1]. Each technique has a preferred substrate that is not compatible with the other technique. Glass microscope slides are the substrate of choice for the light microscope. They allow optical properties to be measured in transmitted light. Glass slides are not desirable substrates for ESEM analysis because they are chemically complex, containing elements such as silicon, sodium, calcium, magnesium, aluminum and potassium (figure 1). Carbon planchets are substrates often used for ESEM analysis. Their chemical simplicity (composed of a single low atomic number element) minimizes interference during x-ray microanalysis of the particles they support. Carbon planchets however, are not useful substrates for light microscopy because they do not allow particles to be analyzed in transmitted light. Substrate incompatibility between these two microanalysis techniques presents a problem when the sample size or quantity is limited. In this case, analysis using both techniques requires material to be transferred from one substrate to another. Transferring samples between substrates is a time consuming and often difficult task during which the particle(s) of interest may be lost.

At the National Institute of Standards and Technology (NIST), we have prepared specialty glass substrates that allow particles mounted on a single substrate to be analyzed using both the light microscope and the ESEM. We have made 3 glasses starting with pure borate $\left(\mathrm{B}_{2} \mathrm{O}_{3}\right)$ glass. Although borate glass is ideal for our purpose, it is not particularly stable under atmospheric conditions. Borate glass absorbs moisture from air, and the surface tends to "frost" over time. To minimize this effect, we made 2 additional glasses to which we added materials to stabilize the glass. To one glass we added $10 \%$ (weight percent) lithium $\left(\mathrm{Li}_{2} \mathrm{O}\right)$ and to the other we added both $10 \%$ lithium $\left(\mathrm{Li}_{2} \mathrm{O}\right)$ and $5 \%$ scandium $\left(\mathrm{Sc}_{2} \mathrm{O}_{3}\right)$. Scandium was selected as an additional stabilizing material because it is a relatively low atomic number element that rarely occurs in samples that most people analyze. To make glass substrates, we first proportion and mix the starting materials $\left(\mathrm{B}_{2} \mathrm{O}_{3}, \mathrm{LiO}_{2}, \mathrm{Sc}_{2} \mathrm{O}_{3}\right)$. The thoroughly mixed starting materials are then placed into a platinum crucible and put into the melt furnace. Borate glass has a relatively low melting point (compared to silicate glass) and for these materials melting temperatures ranged from approximately $1000{ }^{\circ} \mathrm{C}$ to $1200{ }^{\circ} \mathrm{C}$. Once the starting materials are melted, the molten liquid is homogenized by stirring with platinum-rhenium stirrers. The homogenized melt is then poured into a $25.4 \mathrm{~mm}(1 \mathrm{inch})$ diameter cylindrical mold. Upon cooling, the glass solidifies and is removed from the mold and annealed at temperatures ranging from $450{ }^{\circ} \mathrm{C}$ to $500{ }^{\circ} \mathrm{C}$. The glass cylinder is then 
cooled to room temperature and sectioned to make substrates. The substrates are mechanically ground and polished on both sides to maximize transparency for the purpose of light microscopy.

Figures 1 and 2 show energy dispersive x-ray spectra (EDS) collected from the surface of a typical glass microscope slide and a low background borate glass substrate respectively. These spectra were collected in the Phillips Electroscan $2020{ }^{*}$ ESEM at $20 \mathrm{kV}$, and $266 \mathrm{~Pa}$ ( 2 Torr) water vapor pressure. We used a long working distance gaseous secondary electron detector (GSED) and a Kevex Sigma EDS detector. From these spectra, one can see that borate glass provides low background substrates for x-ray microanalysis in the ESEM. For borate and lithium borate glass, the only element that may interfere with particle analysis is oxygen.

Low background borate glass substrates are useful in situations where light microscopy and x-ray microanalysis are desired from samples of limited quantity. They should also find use in situations where the sample is of such value that the analyst does not want to risk remounting the sample onto a different substrate. An additional advantage that borate glass substrates has is that borate allows the detection and analysis of carbon in the samples they support which is impractical with carbon planchets.

\section{References}

[1] J.I. Goldstein et al., Scanning Electron Microscopy and X-Ray Microanalysis, New York, 1992.

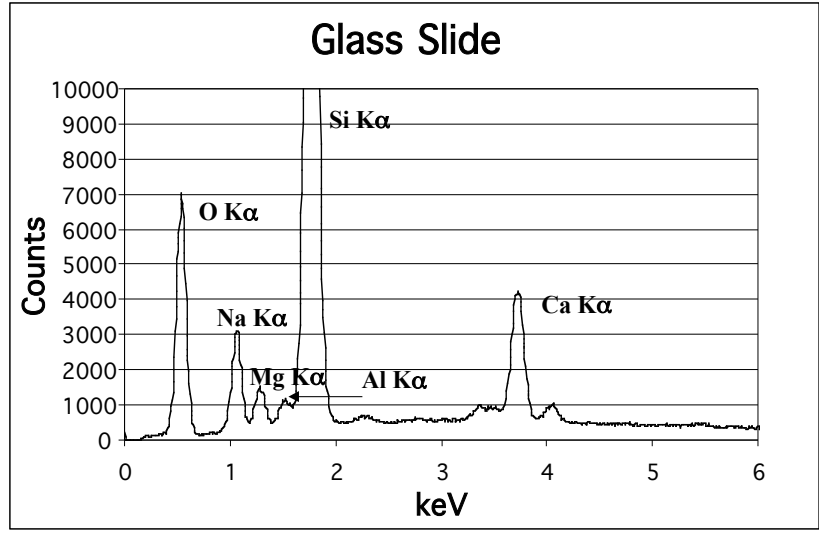

FIG. 1

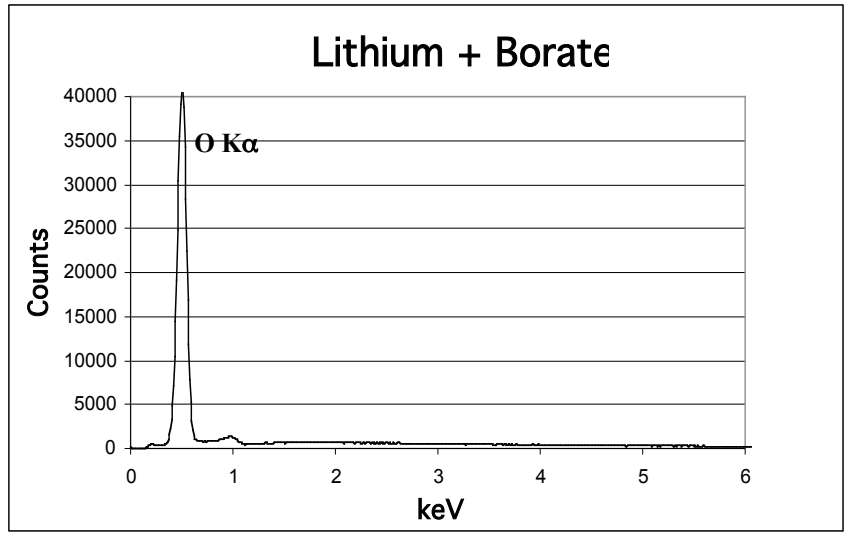

FIG. 2

FIG. 1. EDS of a conventional glass microscope slide. The spectrum was collected for 200 seconds in the ESEM using a long working distance GSED, an accelerating voltage of $20 \mathrm{kV}$ and a water vapor pressure of $266 \mathrm{~Pa}$ (2 Torr).

FIG. 2. EDS of a lithium borate glass substrate ( 10 weight percent $\left.\mathrm{Li}_{2} \mathrm{O}\right)$. The spectrum was collected under the same conditions as fig 1.

\footnotetext{
* Certain commercial equipment, instruments, or materials are identified in this report to specify adequately the experimental procedure. Such identification does not imply recommendation or endorsement by the National Institute of Standards and Technology, nor does it imply that the materials or equipment identified are necessarily the best available for the purpose.
} 